\title{
2ªeunion Extraordinaria
}

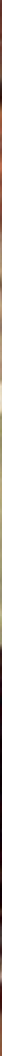




\title{
Dependencia financiera de las haciendas públicas en México, 2004-2016 \\ Financial dependence on public finances in Mexico, 2004-2016
}

\author{
Juan Carlos García Galindo \\ Auditoría Superior de la Federación y \\ Facultad de Economía de la Universidad Nacional Autónoma de México (UnAm, México) \\ Correo electrónico: carlos.galindo.g@outlook.com
}

(Recibido: 05/08/2019. Aceptado para publicación: 23/01/2020)

DOI: 10.22201/fe.24484962e.2019.8.14.2

\section{RESUMEN}

La descentralización fiscal implica problemas asociados a los principios de subsidiariedad y correspondencia fiscal, por lo que se plantea el estudio de la dependencia financiera como una situación estructural del actual Sistema Nacional de Coordinación Fiscal y sus incentivos de distribución de recursos federalizados. Para el análisis se adopta una concepción neoinstitucionalista del Estado aplicada a un gobierno federal. Se contextualiza la situación de las haciendas públicas subnacionales para determinar un Índice Estatal de Dependencia Financiera y se propone una modernización institucional para la transición hacia un federalismo hacendario, donde se incluyan en la agenda los temas de pasivos contingentes, fortalecimiento administrativo y la creación de una plataforma nacional de datos hacendarios, asimismo se exhorta a una Segunda Convención Nacional Hacendaria para replantear los mecanismos de distribución. Palabras clave: dependencia, coordinación fiscal, transferencias, descentralización, corresponsabilidad, subsidiariedad, federalismo fiscal, haciendas públicas, subnacional.

\section{ABSTRACT}

Fiscal decentralization involves problems about principles of subsidiarity and fiscal correspondence, therefore the study of financial dependence is proposed as a structural situation of the current National System of Fiscal Coordination and its incentives for federalized resources distribution, it adopts a neo-institutionalist conception of the state and a federal of the government. The situation of subnational public finances is contextualized to determine a State Index of Financial Dependency and institutional modernization is proposed for the transition towards a tax federalism, where the issues of contingent liabilities, administrative strengthening and the creation of a national tax data platform, also calls for a Second National Tax Convention to rethink the distribution mechanisms. Keywords: dependency, fiscal coordination, transfers, decentralization, co-responsibility, subsidiarity, fiscal federalism, public finances, subnational.

JEL Classification: $\mathrm{H}, \mathrm{H} 1$.

Clasificación JEL: H, H1.

๑) 2021 Universidad Nacional Autónoma de México, Facultad de Economía. Este es un artículo Open Access bajo la licencia Creative Commons Attribution-NonCommercial-NoDerivatives 4.0 International. 
Se nos ha censurado de que proponíamos un gobierno federal, en el nombre, y central en la realidad (Servando Teresa de Mier). Moreno (1997, p. 305)

\section{INTRODUCCIÓN}

$\mathbf{M}$ éxico, como un país federal, se ha caracterizado por concentrar los ingresos públicos más importantes para el gobierno federal, como consecuencia inmediata del pacto fiscal que implica la coordinación nacional y por cuestiones de eficiencia económica. Así también, a los gobiernos estatales se les asocia con bajos recursos públicos y una dependencia de las transferencias federales, aparentemente cada vez mayor.

La coordinación fiscal, el gran tema de las finanzas públicas, en su evolución ha arraigado problemas sistémicos y estructurales; por un lado, inherentes a los mecanismos fiscales de distribución de transferencias de las que se vale el pacto fiscal en nuestro país, y por otro, los relacionados con la propia gestión de los gobiernos subnacionales.

El tema de la dependencia financiera de los gobiernos estatales en México se plantea como una consecuencia del diseño del pacto fiscal, supone de manera concreta un problema real de vulnerabilidad fiscal y pérdida de soberanía de los gobiernos estatales. Se propone esta situación como una condición de precaria capacidad de respuesta ante la satisfacción de necesidades de orden público de los individuos en su calidad de ciudadanos-contribuyentes.

Es por lo anterior que se analiza el Sistema Nacional de Coordinación Fiscal (SNCF) para conocer el grado de autonomía/dependen- cia de las Haciendas Públicas Estatales respecto de la Federación en materia de ingresos. La aportación de este artículo radica en medir la dependencia financiera en sus dos dimensiones (amplia y estricta), así como contextualizar sus causas históricas, la evolución financiera de las entidades federativas y las relaciones intergubernamentales que de ésta derivan, contenidas en el desarrollo del pacto fiscal.

El análisis se realizó para el periodo comprendido de 2004 a 2016, a manera de mostrar la evolución del pacto fiscal a raíz del evento más importante en materia de coordinación fiscal de este siglo, la Primera Convención Nacional Hacendaria; esto último por ser el año del cual se disponían los datos más recientes cuando se recabó la información.

El presente ensayo se divide en los apartados descritos como sigue: en el primero se enmarcan las relaciones entre agentes (órdenes de gobierno) bajo un enfoque neoinstitucionalista; en el segundo se contextualiza la coordinación fiscal en el foro más importante en materia hacendaria como el antecedente inmediato de la actual distribución de recursos federalizados; en el tercer apartado se realiza un análisis de los rubros de ingresos de las entidades federativas y se presentan los datos más relevantes; en el cuarto apartado se presentan los cálculos de dos índices para medir el nivel de dependencia financiera de las entidades federativas de 2004 a 2016; por último se plantean las conclusiones $y$ recomendaciones.

\section{EL NEOINSTITUCIONALISMO ECONÓMICO BAJO UN ENFOQUE FEDERALISTA}

Como sustento teórico del presente ensayo se adoptan: una concepción neoinstitucio- 
nalista del Estado y una federalista del gobierno, donde este último y su accionar son endógenos al sistema económico.

Se utiliza este enfoque heterodoxo para efectuar un estudio con mayor grado de realismo, en el cual no prevalecen los equilibrios, donde el mercado y la hacienda pública son instituciones de provisión de bienes y servicios, las cuales pertenecen a una matriz institucional, y pueden ser eficientes o ineficientes. En este sentido, se realiza un estudio empírico con base en un análisis positivo, en el cual se toman en cuenta factores primordialmente económicos, sin omitir la incidencia de factores históricos, políticos e institucionales.

Bajo este enfoque (neoinstitucionalismo), el Estado es capaz de crear y operar instituciones que afectan las relaciones económicas, al mismo tiempo que vigila el cumplimiento de las reglas que regulan el intercambio, cuya eficacia depende del poder coercitivo del Estado (Ayala, 1996, p. 316). Asimismo, en el marco de la descentralización fiscal (federalismo), las partes integrantes de un Estado federal obtienen mayores ingresos al tener arreglos fiscales que si no los tuvieran. En el federalismo cada nivel de gobierno asume las funciones que mejor puede desempeñar, considerando el sentido espacial de los beneficios y los costos de sus residentes (Principio de subsidiariedad), y se ocupa en la que es más eficiente (mayor beneficio con menor costo), es este carácter del federalismo el que representa la multiplicidad de la unidad (Peña y Wence, 2011).

Existe un enfoque alternativo del federalismo, asociado con el neoinstitucionalismo económico, que retoma a la descentralización fiscal como una alternativa de sostener una economía de mercado, productiva y en crecimiento. Es el "federalismo que preserva el mercado" de Weingast (1995) en el cual: a) los gobiernos descentralizados tienen la principal responsabilidad reguladora de la economía;

b) el sistema constituye un mercado común, y

c) los gobiernos descentralizados enfrentan restricciones presupuestarias rígidas.

Es de este último punto de donde surge la importancia del estudio de la dependencia financiera para los niveles descentralizados. Se recalca que una rígida restricción presupuestaria implica que los gobiernos descentralizados deben depender de las fuentes de ingreso que le hayan sido asignadas, enfatizando la importancia de la disciplina financiera de la autofinanciación, situación en la que deben depender básicamente de sus propias fuentes de ingresos (Weingast, 1995, p. 6).

Para Weingast (1995), la frecuente dependencia financiera de las haciendas públicas locales se traduce en decisiones políticas de una negociación entre los niveles descentralizados y el central, y no basadas en los beneficios económicos de la descentralización.

En palabras de Lewis y Martin (1956): "la debilidad del gobierno local en relación con el gobierno central es uno de los fenómenos más llamativos de los países subdesarrollados". Históricamente, la mayoría de los países subdesarrollados heredaron sistemas centralizados de gobierno (generalmente monarquías absolutas como el caso de la Nueva España) y estos en sus primeros años de independencia fomentaron el centralismo como sinónimo de unidad nacional (Oates, 1999).

El problema de la dependencia financiera, como se ha vislumbrado, está relacionado con los efectos económicos de la descentralización fiscal. Desde la aportación de Oates (1972), la descentralización fiscal es preferible por cuestiones de eficiencia econó- 
mica (eficiencia en el sentido de Pareto), y la aportación institucional de Weingast (1995) se basa en que un sistema federal, como una fuerza disciplinaria que restringe el accionar del sector público (el gasto excesivo y malas conductas fiscales), tiene efectos benéficos para la economía.

En consecuencia, el grado de dependencia financiera asociado a la descentralización fiscal es, en sí mismo, el resultado de un complejo de fuerzas políticas (institucionales) y económicas en las diferentes etapas del desarrollo económico.

\section{DE LA CONVENCIÓN NACIONAL HACENDARIA}

El antecedente inmediato en la evolución del Sistema Nacional de Coordinación Fiscal ${ }^{1}$ es la celebración de la Primera Convención Nacional Hacendaria, como el más reciente foro de discusión nacional en materia de coordinación fiscal.

A principios del siglo xxI, México se hallaba en un momento de transición que trajo consigo la alternancia política, por primera vez el Presidente electo para el periodo 2000-2006 provenía de un partido distinto al Revolucionario Institucional. Ante esta situación, y como un mecanismo democrático de participación ante los problemas comunes que arraigaban las haciendas públicas estatales, se crea la Conferencia Nacional de Gobernadores ${ }^{2}$ (CONAGo).

1 El SNCF se constituyó en 1980 con la publicación de la Ley de Coordinación Fiscal, la cual le otorgó facultades, en su Capítulo Segundo, para armonizar el sistema tributario mediante la coordinación y colaboración.

2 Su antecedente inmediato fue la Asociación Nacional de Gobernadores (Anago) constituida a iniciativa del ex gobernador priista de Tlaxcala, Alfonso Anaya, el 23 de octubre de 1999, para atender principalmente el problema del déficit presupuestal de las haciendas estatales (véase Raúl Jiménez Guillén, ¡Que Paradoja! Anago-Conago,
En un principio la CONAGo surge como un foro permanente para el fortalecimiento del federalismo en México, impulsó una reforma hacendaria que apostaba por la descentralización y la delegación de potestades tributarias a Estados y municipios. ${ }^{3}$

El 20 de agosto de 2003 se emitió en el seno de la conago la Declaración de Cuatro Ciénegas por la cual se convoca, por consenso, a la realización de la Primera Convención Nacional Hacendaria en 2004, ante la necesidad de una renovación del sistema federal mexicano. Se convocó a esta Convención con el objetivo general de construir un federalismo renovado mediante una reforma hacendaria que genere una nueva corresponsabilidad política, económica y administrativa entre los tres órdenes de gobierno, "una reforma hacendaria que conlleve al fortalecimiento de sus haciendas públicas y a la solidez financiera del país".

Los temas que se trataron en la convención se dividieron en siete mesas de análisis y propuestas (véase el cuadro 1).

Los Órganos de la Convención Nacional Hacendaria ${ }^{5}$ llevaron a cabo 437 reuniones de trabajo y se generaron un total de 451 documentos, de los cuales 341 se convirtieron en Propuestas Ejecutivas distribuidas entre las siete mesas de análisis y agrupadas en 50 acciones (Convención Nacional Hacendaria, 2004).

La Jornada de Oriente, 13 de julio de 2015, [en línea] disponible en: <http://www.lajornadadeoriente.com. mx/2015/07/13/que-paradoja-anago-conago/>.

3 David Colmenares Páramo, Por qué se crea la Conago. El Financiero, 25 de noviembre de 2006, [en línea] disponible en: <http://www.elfinanciero.com.mx/opinion/por-quese-crea-la-conago.html $>$.

4 Declaratoria a la Nación y Acuerdos (Convención Nacional Hacendaria, 2004 p. 8).

5 Dirección Ejecutiva, Consejo Directivo, Coordinación Técnica, Mesas de Análisis y Propuestas y Comisiones Técnicas. 


\begin{tabular}{|c|c|c|}
\hline & $\begin{array}{c}\text { CUADRO } 1 \\
\text { MESAS DE ANÁLISIS Y PROPUESTAS POR TEMA } \\
\text { DE LA CONVENCIÓN NACIONAL HACENDARIA }\end{array}$ & \\
\hline & Temas & $\begin{array}{l}\text { Propuestas } \\
\text { ejecutivas }\end{array}$ \\
\hline & Gasto público & 155 \\
\hline Tomasnodalec & Ingresos & 18 \\
\hline remas nodales & Deuda pública & 14 \\
\hline & Patrimonio público & 17 \\
\hline & Modernización y simplificación de la administración hacendaria & 15 \\
\hline institucional & Colaboración y coordinación intergubernamentales & 100 \\
\hline Institucional & Transparencia, fiscalización y rendición de cuentas & 22 \\
\hline
\end{tabular}

Fuente: elaboración propia con información de Convención Nacional Hacendaria (2004).

Se considera que los objetivos centrales de la Convención fueron "generar un capítulo hacendario en la Constitución y una nueva Ley de Federalismo Hacendario", así como "proponer cambios a la legislación secundaria" para transitar las relaciones intergubernamentales hacia un federalismo hacendario que, en otras palabras, se trata de la transformación en derecho positivo de las propuestas de la Convención. No obstante, sólo se materializaron como modificaciones a la legislación los siguientes:

- Transparencia. Se reforman los artículos 3, 6 y 36 de la Ley de Coordinación Fiscal (LCF) para que el calendario, porcentaje, formulas y variables utilizadas del Fondo General de Participaciones (FGP) y el Fondo de Fomento Municipal (FFM) sean publicados en el Diario Oficial de la Federación y los periódicos oficiales de las entidades federativas. ${ }^{6}$

- Ingresos. Se reforma el artículo 9-A de la LCF, $^{7}$ con lo que se faculta a los Estados

6 Decreto por el que se reforman los artículos 3, 6 y 36 de la Ley de Coordinación Fiscal. Diario Oficial de la Federación de México, tomo DXCVIII, no. 10, lunes 14 de julio de 2003, p. 9.

7 Decreto por el que se reforma el artículo 9-A de la Ley de Coordinación Fiscal. Diario Oficial de la Federación de para celebrar convenios de colaboración administrativa, para recibir el $100 \%$ de los ingresos por puentes de peaje operados por los mismos (haciendo participar a sus municipios con el 50\%).

- Gastos. Se reforma el tercer párrafo del artículo 44 de la $\mathrm{LCF}^{8}$ para incluir criterios poblacionales, penitenciarios y de modernización tecnológica al Fondo de Aportaciones para la Seguridad Pública (FASP).

Estas modificaciones a la Ley quedaron rebasadas por los ambiciosos objetivos perseguidos por esta Convención; la modificación esperada era el marcar la pauta en una transición en las fórmulas de participaciones que fomentara una mayor recaudación propia. Con componentes principalmente resarcitorios se buscaba la distribución clara de los fondos de transferencias, responsabilidad hacendaria en el gasto subnacional, mayor disciplina financiera en el manejo y contratación de la deuda subnacional e incentivos a la transparencia y rendición de cuentas,

México, tomo DCIII, no. 21, martes 30 de diciembre de 2003.

8 Decreto por el que se reforma el artículo 44 de la Ley de Coordinación Fiscal. Publicado en el Diario Oficial de la Federación de México, tomo DCXVII, no. 8, jueves 10 de febrero de 2005. 
entre otros, por lo cual se concluye que no se logró un cambio sustancial que fortaleciera las finanzas públicas ni se identifican las bases de una transición a un federalismo hacendario.

\section{SITUACIÓN FINANCIERA DE LAS ENTIDADES FEDERATIVAS}

Las entidades federativas en México tienen la característica de ser heterogéneas tanto por su nivel de desarrollo, orografía, cultura, nivel de bienestar, pobreza, entre otras, como, y no menos importante, su heterogeneidad fiscal. ${ }^{9}$ Para entender la estructura y funcionamiento, así como los desequilibrios y retos que enfrentan las haciendas estatales es necesario partir de la realización de un diagnóstico que refleje la situación de las mismas.

Por este motivo, y como preludio a la profundización en el estudio de la dependencia financiera, en la inmediata sección se realiza un análisis de la situación financiera de las haciendas públicas estatales. Lo que se pretende destacar con este análisis es la naturaleza de la información disponible para México; la heterogeneidad y desigualdad en la que se encuentran las entidades federativas en materia de ingresos, así como medir la condición de estos en tres dimensiones: incidencia, ingresos de los que se valen las entidades federativas y su estructura relativa; la profundidad e intensidad de las desigualdades interjurisdiccionales en esfuerzo fiscal, y la proporción entre ingresos propios e ingresos por transferencia.

Para el análisis realizado en esta sección, el acomodo de las entidades federativas atiende a los niveles de pobreza multidimensional

9 Véase Mendoze y Martínez-Vázquez (2000). (debido a su estrecha relación con los ingresos públicos) reportados por el Consejo Nacional de Evaluación de la Política de Desarrollo Social (CONEVAL) en 2010, siendo Nuevo León la entidad con menor porcentaje de pobres (21.0\% del total de su población) y Chiapas la entidad con mayor porcentaje de pobres ( $78.5 \%$ del total de su población); la media nacional se sitúa en $46.1 \%$ de la población nacional estimada a mitad de 2010.

En el periodo 2004-2016, los ingresos medios totales a nivel nacional tienen la estructura siguiente:

- Ingresos propios, $11.2 \%$ (excluyendo el caso atípico de la Ciudad de México, que apenas alcanza el 7.5\%).

- Ingresos por transferencias, $64.5 \%$.

- Otros ingresos, $24.3 \%$, todos respecto del total.

Durante los años referidos, los ingresos de las entidades han tenido un comportamiento dinámico; en términos reales, los ingresos medios totales crecieron $83.6 \%$ acumulado, al pasar de 24247866.0 miles de pesos constantes en 2004 a 44531560.8 miles de pesos constantes en 2016, es decir, en el periodo de 2004 a 2016 los ingresos totales crecieron a una tasa de $4.8 \%$ anual (véase la gráfica 1 ).

\subsection{Ingresos propios}

Se consideran como ingresos propios únicamente a los impuestos, derechos, productos $\mathrm{y}$ aprovechamientos, por tratarse de potestades exclusivas de los Estados y recaudarse directamente de la jurisdicción sobre la que tienen competencia. En términos reales, los ingresos propios medios presentaron un crecimiento acumulado de $154.7 \%$, al pasar de 2998890.0 miles de pesos constantes en 2004 a 7637591.8 miles de pesos constantes 
GRÁFICA 1

\section{EVOLUCIÓN DE LOS INGRESOS MEDIOS DE LAS ENTIDADES FEDERATIVAS, 2004-2016}

(miles de pesos a precios del 2010)

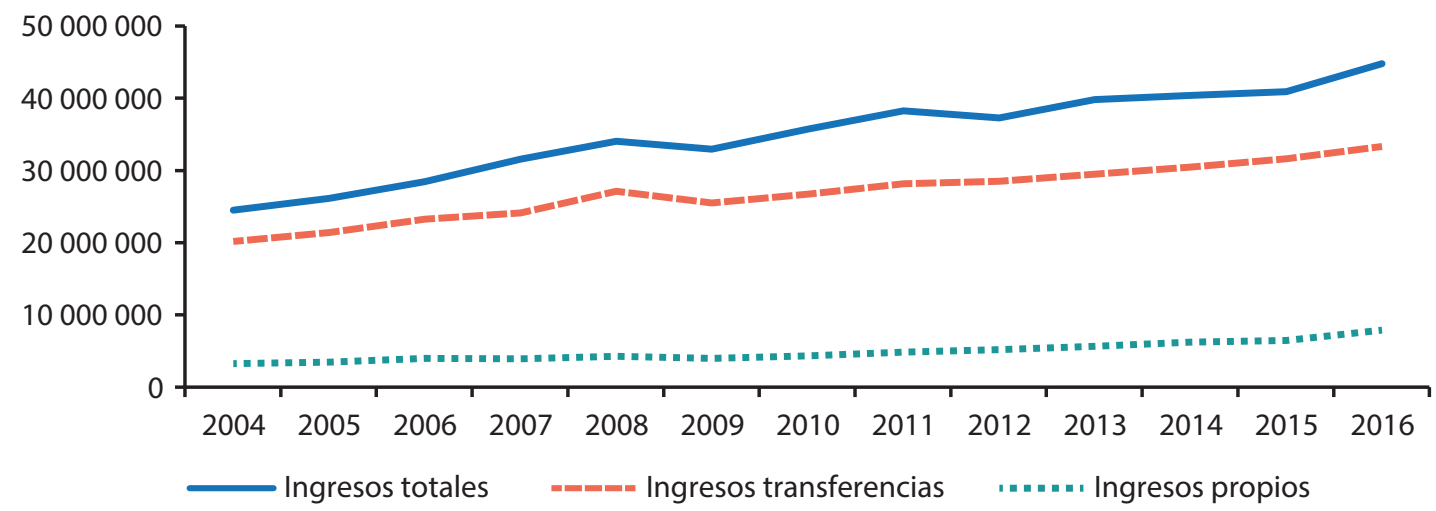

Fuente: elaboración propia con datos del Instituto Nacional para el Federalismo y el Desarrollo Municipal (INAFED) y leyes de ingresos de las entidades federativas para el ejercicio fiscal 2016.

\section{GRÁFICA 2 \\ INGRESOS PROPIOS PROMEDIO, 2004-2016}

(miles de pesos a precios de 2010)

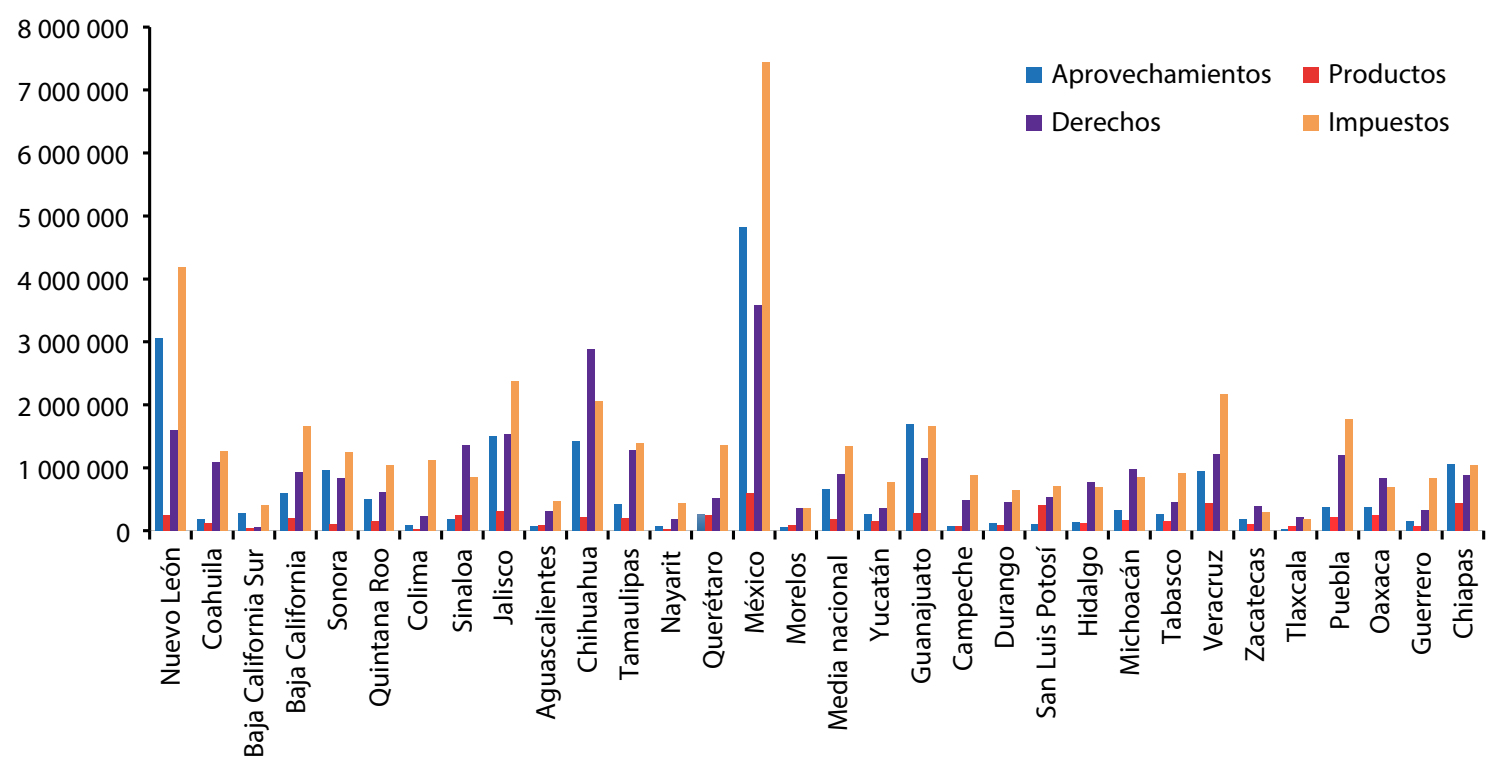

Fuente: elaboración propia con datos del INAFED y leyes de ingresos de las entidades federativas para el ejercicio fiscal 2016.

en 2016, lo que equivale a un crecimiento promedio anual de $7.5 \%$. Tan sólo once entidades $^{10}$ se encuentran por encima de la

10 Nuevo León, Baja California, Sonora, Jalisco, Chihuahua, Tamaulipas, México, Guanajuato, Veracruz, Puebla y Chiapas. media nacional en recaudación (3 115093.6 miles de pesos constantes en promedio) y de estos siete concentran el $53.6 \%$ de los ingresos propios totales (véase la gráfica 2). Asimismo, en promedio para el periodo, tuvieron la estructura porcentual presentada en el gráfica 3. 
GRÁFICA 3

ESTRUCTURA PORCENTUAL

PROMEDIO, 2004-2016

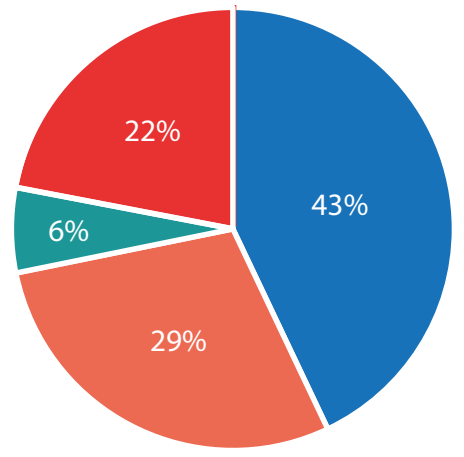

- Impuestos

Derechos

- Productos

- Aprovechamientos

Fuente: elaboración propia.

Como se observa en la gráfica 3, los impuestos son el rubro más importante de los ingresos propios, ${ }^{11}$ para el periodo mostraron un crecimiento promedio anual del $8.56 \%$ y un acumulado de $190.95 \%$ al pasar de 1200046.6 miles de pesos constantes a 3491520.1 miles de pesos constantes.

\subsection{Ingresos por transferencia}

El otro gran rubro de ingresos estatales y que, en el periodo de estudio, ha sido la fuente de ingresos más importante para las entidades federativas es el de transferencias federales, identificadas en el Presupuesto de Egresos de la Federación en su clasificación administrativa con los Ramos Generales 28 (Par-

11 Por su naturaleza, los ingresos por impuestos son los únicos que están en control directo de las haciendas estatales y el monto depende del desarrollo económico, de su capacidad administrativa, de su esfuerzo fiscal, entre otros, por lo cual, el análisis recae en este rubro. Si bien los Estados en sus funciones de derecho público pueden incrementar la recaudación de ingresos no tributarios, el monto que puedan alcanzar depende de su capacidad administrativa (como el caso de los derechos y aprovechamientos). ticipaciones Federales) y 33 (Aportaciones Federales). Como se ha mencionado hasta ahora, las participaciones son recursos de libre ejecución de las entidades federativas y de acuerdo con la teoría de la descentralización se utilizan como mecanismos para combatir los desequilibrios verticales del sector público. Por su parte, las aportaciones son recursos etiquetados para cubrir diferentes rubros del desarrollo económico y social de la población, utilizados para disminuir las disparidades regionales (desequilibrio horizontal).

En términos reales, los ingresos promedios por transferencias presentaron un crecimiento acumulado de $66.1 \%$, al pasar de 19916209.2 miles de pesos constantes en 2004 a 33070516.8 miles de pesos constantes en 2016 , lo que equivale a un crecimiento promedio anual de $3.9 \%$ (véase la gráfica 5).

En promedio para el periodo, las participaciones representaron el 51.81\% (para este caso no se excluye a la Ciudad de México, ya que recibió las transferencias correspondientes a los municipios de acuerdo con la Ley de Coordinación Fiscal) y las aportaciones el 48.19\% (véase la gráfica 4).

\section{GRÁFICA 4 ESTRUCTURA PORCENTUAL PROMEDIO, 2004-2016}

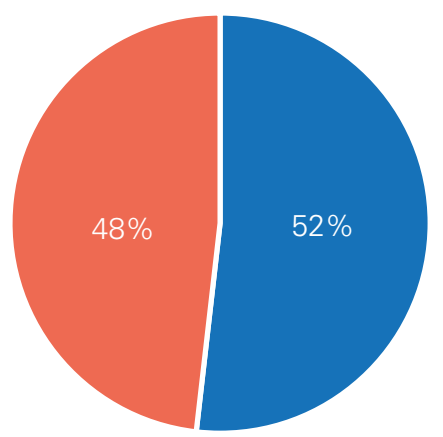

Participaciones Aportaciones

Fuente: elaboración propia. 


\section{GRÁFICA 5}

INGRESOS PROMEDIO POR TRANSFERENCIA, 2004-2016

(miles de pesos a precios de 2010)

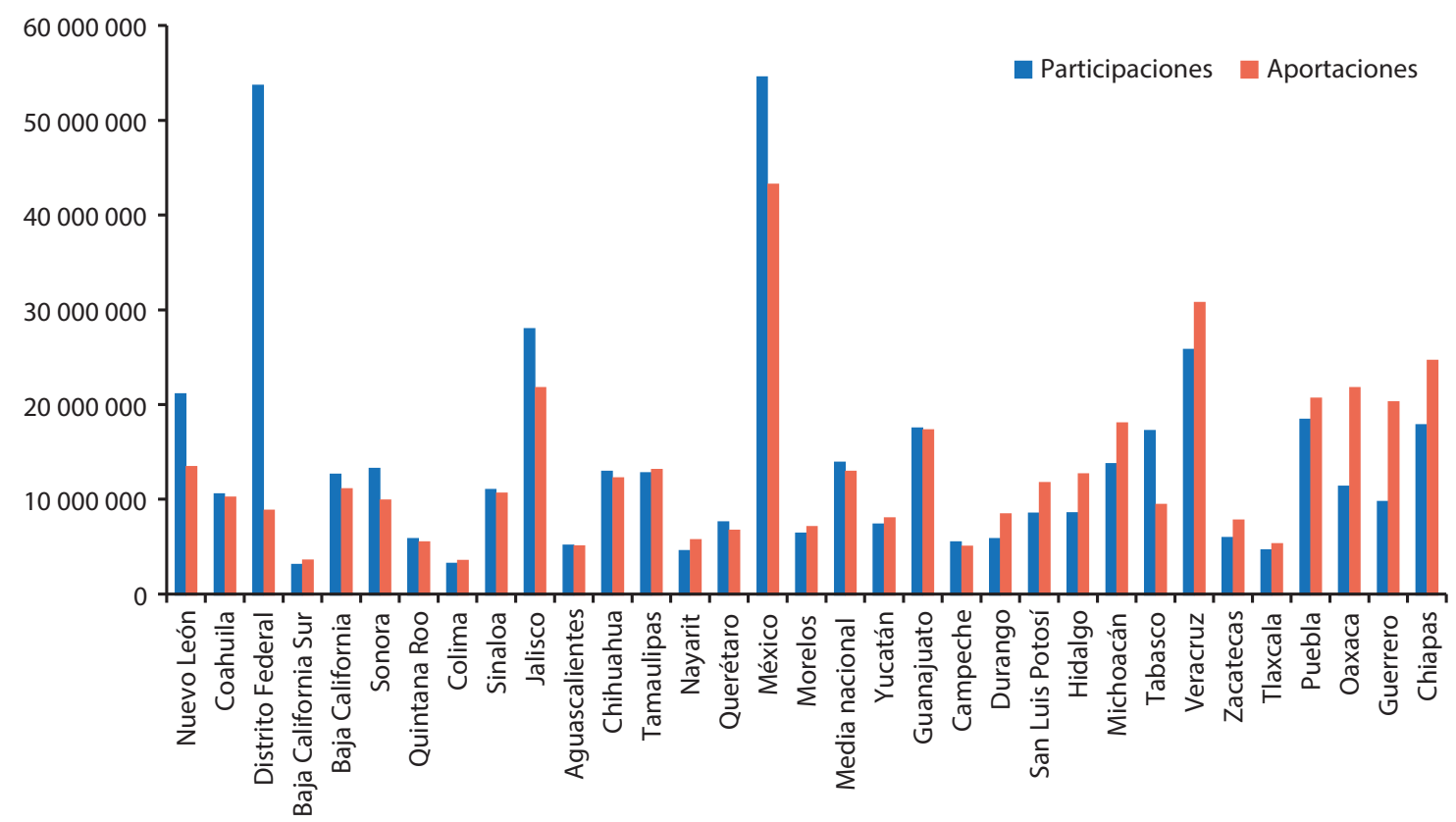

Fuente: elaboración propia con datos de las Estadísticas Oportunas de Finanzas Públicas de la Secretaría de Hacienda y Crédito Público (sHCP) y la Información de Federalismo Hacendario del INAFED.

\subsection{Resultados relevantes}

Del análisis a la situación financiera se desprende que el grueso de los ingresos estatales proviene de transferencias federales, que los ingresos propios en promedio representaron el $11.2 \%$ de los ingresos totales y que la captación por entidad federativa es heterogénea. Se observó que en periodos de recesión económica (2008-2009) y de afectaciones al mercado del petróleo (2012, por su estrecha relación con los ingresos públicos), los ingresos totales tuvieron reducciones considerables debido a que la Recaudación Federal Participable, que funge como piedra angular del SNCF, es la base sobre la que se distribuyen las participaciones, así como el instrumento mediante el cual se relacionan la economía real (actividad económica) y los ingresos públicos.
Respecto de los ingresos propios, se observó que once entidades federativas se encuentran por encima de la media nacional de recaudación (3 115096.6 miles de pesos constantes) y que siete concentran el 53.6\% de los ingresos propios totales. Estados como México, Nuevo León y Veracruz se caracterizaron durante el periodo por su destacada recaudación tributaria y no sólo por su elevado nivel de ingresos por impuestos, pues son los Estados que más potestades tributarias utilizan.

El rubro más importante de los ingresos propios fue, como era de esperarse, el de impuestos, que representaron para el periodo el $42.9 \%$ respecto de los ingresos propios totales, asimismo mostraron una tasa de crecimiento promedio anual de $8.6 \%$.

Las entidades federativas, a raíz del pacto fiscal, aún se valen de impuestos importantes 
sobre los ingresos, el patrimonio, la producción, el consumo y las transacciones y adicionales y otros impuestos, de los cuales se determinó que por cada peso recaudado en promedio para el periodo 2004-2016, se gravarían 86 centavos en función del ingreso de los individuos y no sobre sus decisiones de consumo. A su vez, el impuesto más importante para las entidades federativas fue el Impuesto Sobre Nóminas, el cual pasó de representar el $48.0 \%$ del total de la recaudación estatal promedio en 2004 (año en que sólo 19 Estados cobraban este impuesto) a 64.9\% en 2016 (año en que todos los Estados ya lo cobraban).

Se encuentra que el rubro más importante de ingresos de los Estados, que representó en promedio para el periodo de estudio el $64.5 \%$, se compone en $51.8 \%$ por participaciones y en $48.2 \%$ por aportaciones.

Asimismo, el FGP es la principal fuente de ingresos por participaciones, con una importancia relativa de $70.1 \%$ respecto del total de participaciones. No se omite mencionar que los Fondos de Participaciones se distribuyen, principalmente, mediante una mixtura de criterios resarcitorios/compensatorios, donde los componentes poblacionales e inerciales aseguran al menos un monto tan alto como el recibido en periodos anteriores. Por su parte, los Fondos de Participaciones se distribuyen, especialmente, bajo criterios distributivos, con tres excepciones:

- Fondo de Aportaciones Múltiples (fAM), criterios compensatorios y de avances programáticos.

- FASP, criterios distributivos y de avances programáticos.

- Fondo de Aportaciones para el Fortalecimiento de las Entidades Federativas (FAFEF), criterios resarcitorios y distributivos.

\section{5. ÍNDICE ESTATAL DE DEPENDENCIA FINANCIERA}

Como se ha adelantado por muchos autores en las últimas décadas, se percibe a la dependencia financiera como una condición de debilidad estructural e institucional de las haciendas estatales en dos sentidos complementarios:

- Como una proporción donde el grueso de los ingresos estatales descansa en transferencias federales.

- Como condición en la que las entidades federativas, por sus propias potestades, no pueden hacerles frente a sus obligaciones de gasto, ambas conferidas a raíz del pacto fiscal federal (en algunos casos ni siquiera pueden mantener el gasto de su operación propia).

La dependencia financiera se concibe como la incapacidad de la entidad federativa para contar con recursos suficientes derivados de renglones tributarios exclusivos, así como el obstaculizado manejo de su patrimonio y la indisposición de su hacienda. ${ }^{12}$

La pregunta obligada en este punto es: ¿qué determina esta condición denominada dependencia financiera?, la cual se afirma que con certeza ha prevalecido en las entidades federativas durante el periodo de estudio y, probablemente, desde que se instauró este mecanismo de transferencias federales.

\footnotetext{
12 Se realiza un atento recordatorio al lector que esta definición surge como una analogía a la proporcionada por Quintana (2008, p. 195) en su definición sobre autonomía financiera municipal.
} 


\subsection{Determinantes de la dependencia financiera}

En los estudios contemporáneos sobre este tema destaca la investigación realizada por Peña y Bojórquez (2012), publicada por el INAFED. En su búsqueda por identificar las variables que determinan la autonomía financiera municipal, ${ }^{13}$ los autores encuentran que está determinada por las variables siguientes (acomodadas jerárquicamente de acuerdo con su importancia en el impacto sobre la autonomía financiera):

1. Variables socioeconómicas, el índice de marginación y el logaritmo natural de la población.

2. El indicador de actualización del catastro en su variable esfuerzo fiscal.

3. La variable vigilancia y participación ciudadana, como un indicador del porcentaje de participación electoral.

4. La importancia de la deuda en la liquidez y el número de computadoras por funcionario público, ambas de la variable capacidad administrativa.

Peña y Bojórquez (2012) se refieren a la dependencia financiera como una condición de insolvencia del gasto público local, enfatizando la relación intrínseca de estos con los ingresos propios (la número dos descrita al inicio del presente trabajo). Concluyen que la dependencia financiera es en parte explicada "por causas estructurales difícilmente controladas desde el ámbito local de gobierno" (Ibídem, p. 40).

El INAFED, a través de su Sistema de Información Hacendaria ${ }^{14}$, publica anualmente una serie de indicadores financieros y de desempeño de las administraciones estatales y municipales, en los cuales se encuentran dos indicadores similares al propuesto, el primero respecto de las participaciones y el segundo en relación con las aportaciones. Dentro de sus principales resultados se encuentran los mostrados en el cuadro 2 .

Como se vislumbra, estos resultados no son compatibles con los datos hasta ahora encontrados sobre el peso relativo de participaciones y aportaciones en el total de los ingresos estatales; sin embargo, se mencionan a manera de contrastar los resultados obtenidos en este trabajo y como un punto de referencia de índices similares.

El alcance de esta investigación escapa a la identificación de las variables que determinan la condición de dependencia finan-

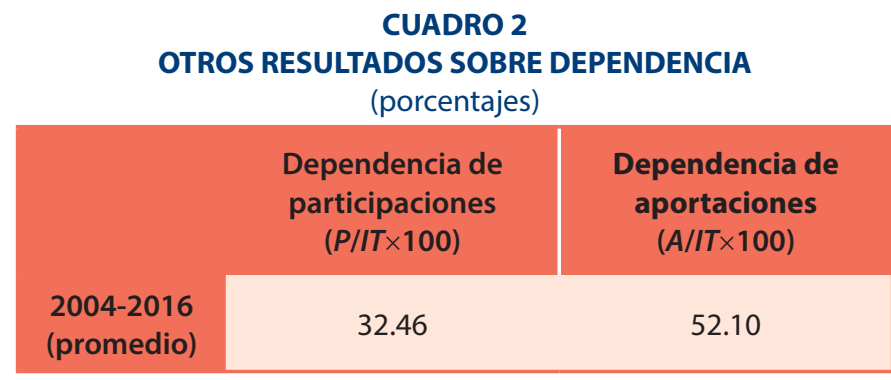

Fuente: Sistema de Información Hacendaria del INAFED.

13 Pese a que esta investigación se centra en el orden de gobierno municipal, es una propuesta que se puede extender al orden estatal, por el tratamiento metodológico riguroso y el enfoque conceptual utilizado.
14 Disponible a través de: Instituto Nacional para el Federalismo y el Desarrollo Municipal <https://www.gob.mx/ inafed $>$. 
ciera estatal; no obstante, se tienen indicios cualitativos sobre sus determinantes en diferentes dimensiones del problema, con lo cual se infiere que esta condición se explica, en parte, por las variables siguientes:

- Esfuerzo fiscal, una variable que determina la perseverancia de las haciendas estatales en recaudar efectivamente impuestos que fortalezcan sus finanzas, así como los mecanismos y las bases gravables de los cuales disponen efectivamente y que determinan el límite de su capacidad fiscal. En la literatura revisada se encuentra que hay un consenso respecto a la medición de esta variable: ${ }^{15}$

Esfuerzo fiscal $=\frac{\text { Recaudación efectiva }}{\text { Capacidad fiscal }} 16$

- Capacidad administrativa: se refiere a variables que determinan, en su caso, la aptitud de los gobiernos de atender, con los recursos materiales y humanos disponibles, las obligaciones gerenciales y de gasto conferidas a su jurisdicción, para la cual se utilizan variables como profesionalización de los servidores públicos, disponibilidad de infraestructura y utilización de tecnologías de la información.

- Variables socioeconómicas: concernientes al grado de marginación y pobreza de los individuos, el nivel medio de renta del contribuyente, el producto interno bruto estatal per cápita, así como algún indicador poblacional que mida la incidencia

15 Véanse al respecto Sobarzo (2006), Sour (2008) y Peña y Bojórquez (2012).

16 La capacidad fiscal es definida por Martínez Vázquez y Boex (1997, p. 2) como"la habilidad potencial del gobierno de una región para recaudar ingresos de sus propias fuentes y pagar por una canasta estandarizada de bienes y servicios públicos" (citado por Sour, 2004). de esta variable en las transferencias federales.

- Ingresos futuros: se trata de las obligaciones financieras (deuda pública) y pasivos contingentes, los cuales comprometen los ingresos futuros de libre disposición de las entidades federativas (ingresos propios, FAFEF y participaciones; en algunos casos también se comprometen, en proyectos de infraestructura, ingresos futuros de fondos de aportaciones como el $\mathrm{FAM}^{17}$ ).

- Transparencia y rendición de cuentas: variables que determinen el grado de participación ciudadana y su incidencia en la provisión de bienes públicos, así como indicadores de fiscalización y mecanismos que aseguren la rendición de cuentas a nivel estatal, por ejemplo, el Subíndice de Transparencia Estatal.

El objetivo de este trabajo es la determinación de un nivel de dependencia financiera estatal que, de acuerdo con las hipótesis realizadas, refleje que los Estados dependen financieramente de las transferencias federales, lo cual vuelve, en cierta medida, vulnerables sus haciendas públicas con una menor capacidad de respuesta.

Si bien se tienen ubicados los componentes de los ingresos estatales, el verdadero derrotero en el tema radica en identificar las variables que inciden en la dependencia financiera, desarrollar modelos cuantitativos que incorporen mayor certeza a su medición y promover mejores prácticas fiscales en las haciendas públicas que equilibren la relación ingreso-gasto al tiempo que se cierren las brechas económicas entre las entidades federativas.

\footnotetext{
17 Para una profundización en el tema véase Auditoría Superior de la Federación (2017).
} 
Se optó por medir la dependencia financiera como una proporción de los ingresos por transferencias en los ingresos totales, que es una manera tradicional de cuantificar este comportamiento, adicionando la dimensión amplia, donde no se incluyen las participaciones por su carácter resarcitorio. No se incluyeron variables administrativas, socioeconómicas, esfuerzo fiscal, entre otras, debido a que el alcance de la investigación estuvo en función de la información pública disponible a nivel nacional.

\subsection{Resultados: Índice Estatal de Dependencia Financiera}

De acuerdo con la literatura revisada, los índices de autonomía/dependencia financiera forman parte de los denominados Índices de Descentralización Fiscal (IDF), los cuales son instrumentos que miden la participación que tienen los niveles subcentrales de gobierno en la actividad económica del sector público, tanto en ingresos como en gasto públicos. ${ }^{18}$

Para cumplir con el objetivo del presente trabajo se realizó el cálculo del Índice Estatal de Dependencia Financiera (IEDF) respecto de los ingresos de las entidades federativas. Dada la naturaleza incondicionada de las participaciones federales (transferencias incondicionadas), que en un primer momento se crearon para "regresar" a los Estados aquellos recursos que dejaron de recibir a raíz del pacto fiscal, algunos autores han planteado que estos recursos deberían ser considerados como ingresos propios de los Estados; $;^{19}$ por

18 David Cantarero, Curso Hacienda Multijurisdiccional, Universidad de Cantabria, España. Presentación disponible en: <http://personales.unican.es/cantared/1.\%20 Esquemas.pdf $>$.

19 Courchene y Díaz-Cayeros (2000) afirman que "la definición más apropiada de ingresos propios incluiría las participaciones incondicionales" (traducción propia), otro lado, es común que en la literatura fiscal se considere sólo como ingresos propios aquellos recursos que derivan de las potestades recaudatorias conferidas a cada Estado (Sour, 2004; Quintana, 2008). Esta diferencia metodológica hace que exista una división en los índices en estrictos y amplios:

- En sentido estricto son aquellos que sólo toman en cuenta como ingresos propios donde dicho nivel de gobierno tiene competencias exclusivas en su gestión.

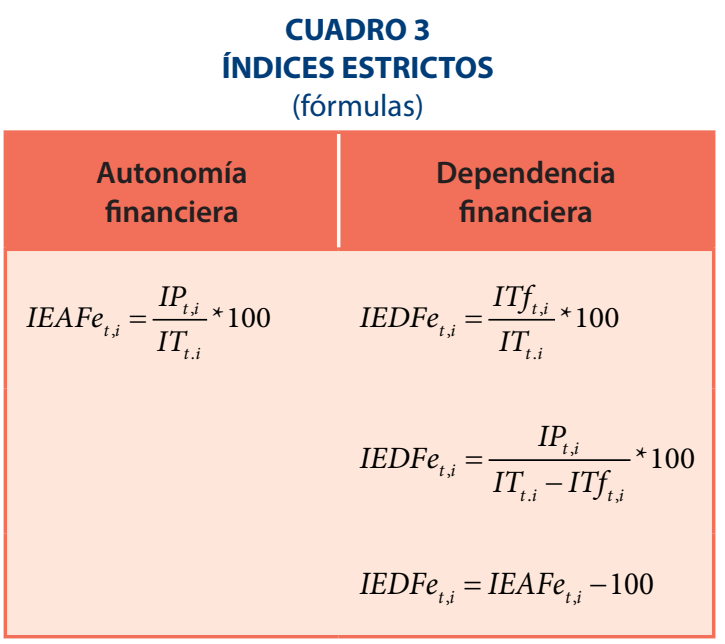

Fuente: elaboración propia con base en fórmulas proporcionadas por el Dr. David Cantarero Prieto de la Universidad de Cantabria, España.

- En sentido amplio incluyen a todos los ingresos que sus competencias de gestión están compartidas con otros niveles de gobierno, es decir, se consideran como ingresos propios a las transferencias incondicionadas (participaciones).

ya que de lo contrario sería una concepción "estrecha"; Colmenares Páramo (1999) recalca el carácter resarcitorio y la libre disposición de las participaciones 


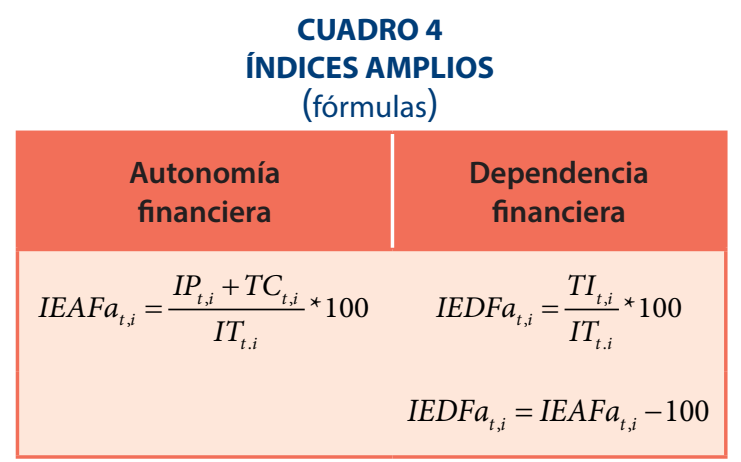

Fuente: elaboración propia con base en fórmulas proporcionadas por el Dr. David Cantarero Prieto de la Universidad de Cantabria, España.

donde $I E A F e_{t, i}$ es el Índice Estatal de Autonomía Financiera estricto en el periodo $t$ de la entidad $i I E D F e_{t, i}$ es el Índice Estatal de Dependencia Financiera estricto en el periodo $t$ de la entidad $i$; $I E A F a_{t, i}$ es el Índice Estatal de Autonomía Financiera amplio en el periodo $t$ de la entidad $i$; $I E D F a_{t, i}$ es el Índice Estatal de Dependencia Financiera amplio en el periodo $t$ de la entidad $i$; $I P_{t, i}$ son los ingresos propios que recaudó la entidad $i$ en el periodo $t ; I T_{t, i}$ son los ingresos totales que recibió la entidad $i$ en el periodo $t ; \operatorname{ITf}_{t, i}$ son los ingresos totales por transferencias que recibió la entidad $i$ en el periodo $t ; T C_{t, i}$ son los ingresos por transferencias condicionadas (participaciones) que recibió la entidad $i$ en el periodo $t$, e $T I_{t, i}$ son los ingresos por transferencias incondicionadas (aportaciones) que recibió la entidad $i$ en el periodo $t$.

Con base en la información recopilada para la situación financiera de las entidades federativas en el periodo de estudio, se muestran los resultados, para el caso de México, de los índices de dependencia y autonomía financiera, en sentido amplio y estricto, como se muestra en la gráfica 6 .

Ya que los ingresos por transferencias representan el grueso de los ingresos totales, al presentar un índice amplio y uno estricto se observan dos panoramas considerable- mente distintos sobre esta condición. Con una visión estricta, prácticamente todas las haciendas estatales son altamente dependientes, con resultados por encima del $80 \%$ de dependencia (excepto la Ciudad de México), y con una concepción amplia que incluye a las participaciones como ingresos propios por su carácter resarcitorio, nos encontramos así con que la mayoría de los Estados está en el rango entre 40-60\% del índice (véase la gráfica 6).

Estados con mayor rezago económico como Guerrero (IDFe = 95.6), Tlaxcala (IDFe =95.0 $)$ y Oaxaca $(I D F e=94.4)$ muestran los niveles más elevados de dependencia financiera estricta, lo cual se explica por los niveles de recaudación tanto estatal como federal. Sin embargo, los Estados que destacaron por su elevada recaudación en impuestos también muestran elevados niveles de dependencia financiera estricta: México $(I D F e=85.7)$, Nuevo León $(I D F e=79.7)$ y Veracruz $(I D F e=92.3)$. Estos resultados, al parecer contradictorios, apuntan a que independientemente del esfuerzo fiscal, esta condición se puede atribuir a factores institucionales del diseño del actual SNCF.

Como se demostró en la sección previa, la Recaudación Federal Participable creció $63.4 \%$ a una tasa acumulada real (al pasar de 1308954928.6 miles de pesos constantes en 2004 a 2139374566.8 miles de pesos constantes en 2016), y la recaudación estatal promedio creció a una tasa acumulada real del 191.0\% (al pasar de 1200046.6 miles de pesos constantes en 2014 a 3491520.1 miles de pesos constantes en 2016).

Por su parte, la evolución promedio de la dependencia financiera en sus dos dimensiones (véase la gráfica 7) arroja que la dependencia financiera estricta tuvo una tasa de crecimiento acumulada de $-6.1 \%$ (al pasar de 91.0 puntos del índice en 2004 a 85.5 


\section{GRÁFICA 6 \\ ÍNDICES DE DEPENDENCIA FINANCIERA, RESULTADOS PROMEDIO \\ POR ENTIDAD FEDERATIVA, 2004-2016}

(porcentajes)

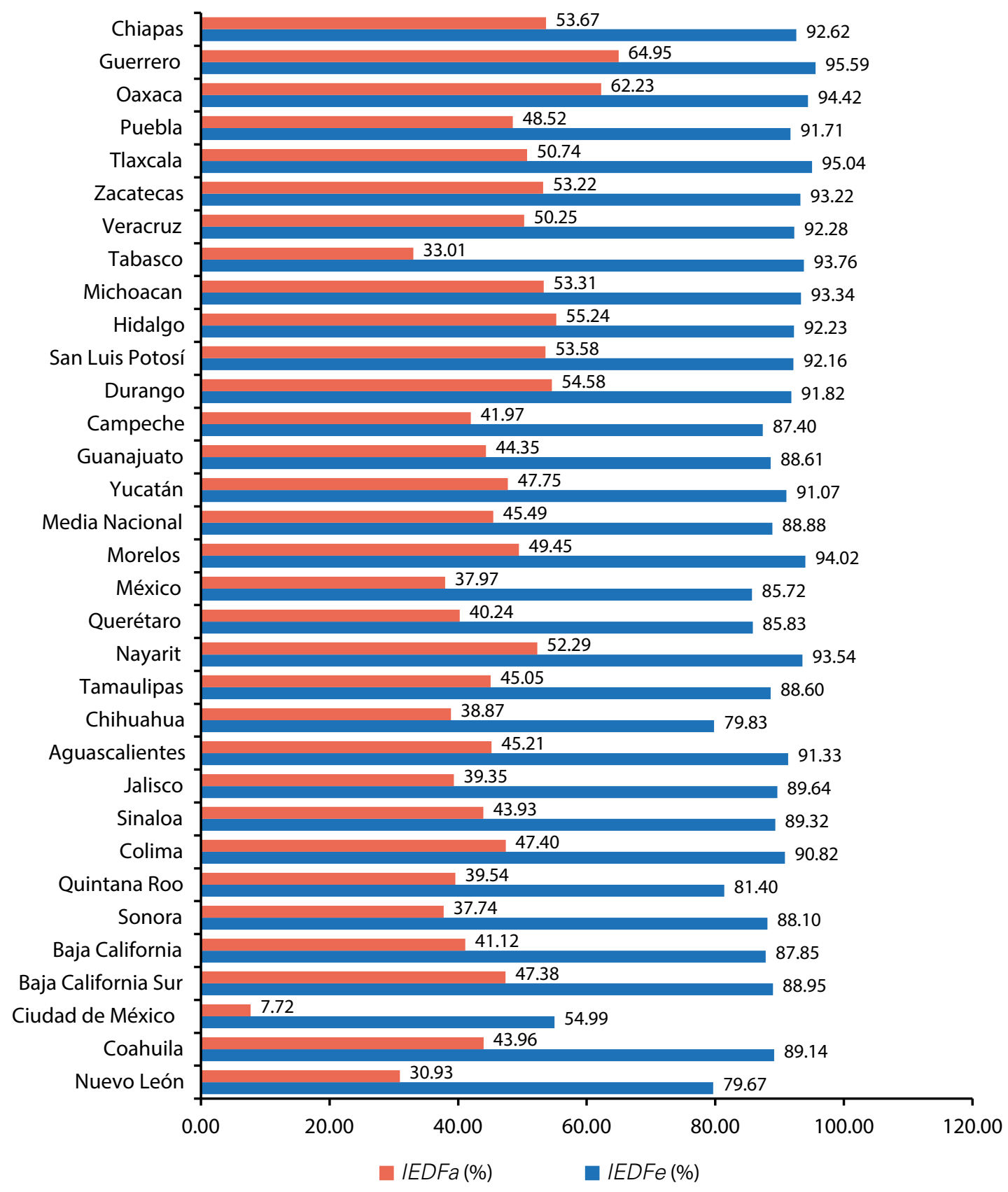

Fuente: elaboración propia con datos de las Estadísticas Oportunas de las Finanzas Públicas de la SHCP, de la Información de Federalismo Hacendario del InAFED y de las Finanzas Públicas Estatales de México (varios años), Cuentas Públicas y Leyes de Ingreso de las Entidades Federativas (varios años) del Instituto Nacional de Estadística y Geografía (INEGI). 
GRÁFICA 7

EVOLUCIÓN DE LA DEPENDENCIA FINANCIERA, PROMEDIO EN ENTIDADES FEDERATIVAS, 2004-2016

(porcentajes)

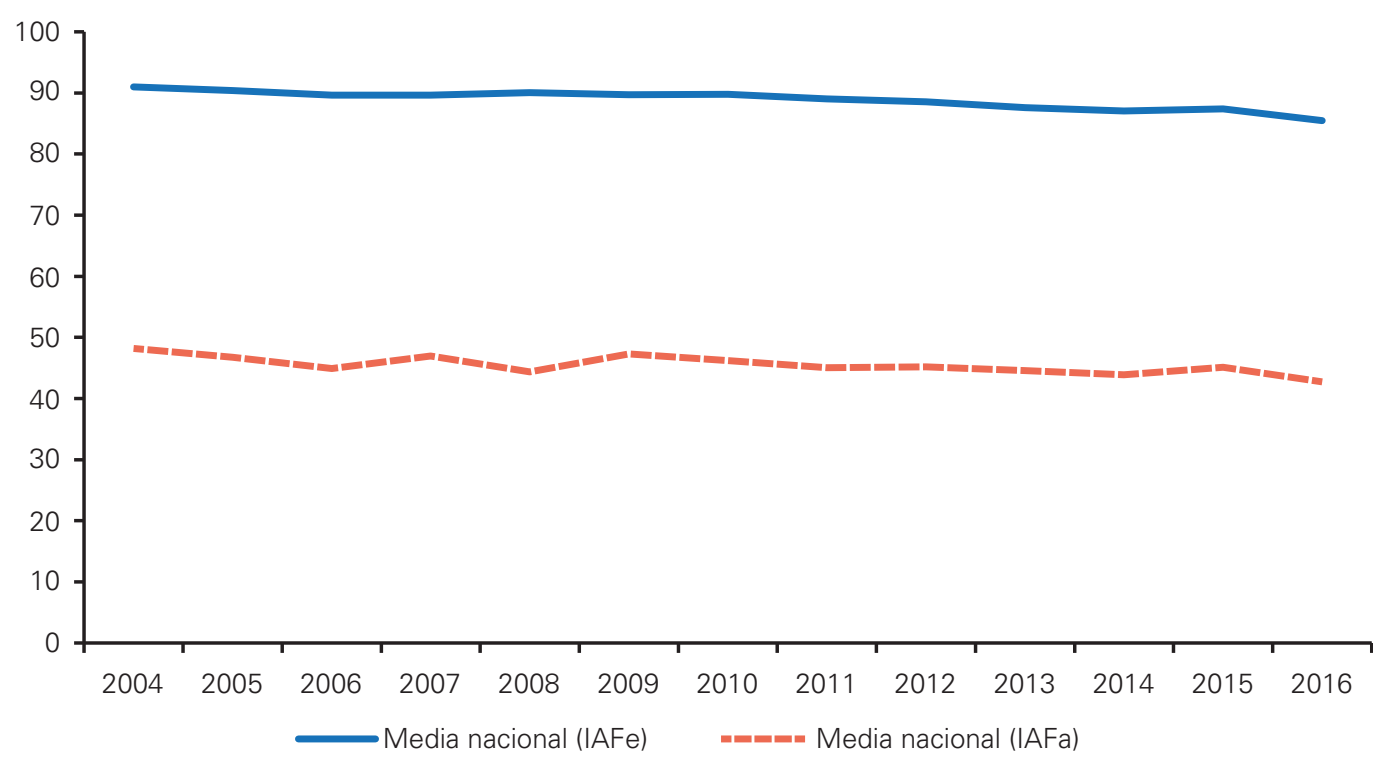

Fuente: elaboración propia con datos de las Estadísticas Oportunas de las Finanzas Públicas de la SHCP, de la Información de Federalismo Hacendario del INAFED y de las Finanzas Públicas Estatales de México (varios años), Cuentas Públicas y Leyes de Ingreso de las Entidades Federativas (varios años) del Instituto Nacional de Estadística y Geografía (INEGI).

puntos del índice en 2016), mientras que la dependencia financiera amplia tuvo una tasa de crecimiento acumulada de $-11.3 \%$ (al pasar de 48.2 puntos del índice en 2004 a 42.7 puntos del índice en 2016).

Si se parte de la premisa de que la recaudación es determinada por la actividad económica y el esfuerzo fiscal de las haciendas estatales, se podría esperar que, en buena medida, la dependencia financiera de las entidades federativas estuviera asociada a la actividad económica de cada jurisdicción y a la capacidad administrativa y de gestión; los datos presentados muestran que, ante altas tasas de crecimiento en la recaudación, la disminución de la dependencia financiera ha sido precaria. Dicho comportamiento se puede atribuir a factores institucionales, y si bien la implementación y el diseño del actual SNCF han contribuido a que la dependencia financiera persista a través del tiempo, se presenta también como un detrimento ante la creciente recaudación tanto federal como estatal.

De la investigación realizada se precisa que la dependencia financiera en sentido amplio es un indicador más coherente con la teoría de la descentralización fiscal, ya que la naturaleza de las participaciones es de "regresar" lo cedido en el pacto fiscal en términos de eficiencia económica y equidad distributiva, dejando únicamente a las aportaciones que no estaban concebidas en el pacto fiscal original ${ }^{20}$ como recursos de los que

20 Los cuales surgieron como una integración de convenios distribuidos en distintos Ramos Generales, bajo el discurso de un compromiso con la descentralización fiscal: de un renovado federalismo (véanse Centro de Estudios de las Finanzas Públicas, 2006 y Chiapa y Velázquez, 2011). 
realmente dependen las haciendas públicas estatales para cubrir las asignaciones de gasto que les fueron conferidas a sus respectivas jurisdicciones a partir de su inclusión en la Ley de Coordinación Fiscal en 1997.

Ya que no se percibe una relación directa entre los Estados que recaudan más impuestos y los que son menos dependientes, los niveles de pobreza de las entidades si se corresponden con los grados de dependencia financiera (véase el cuadro 5); los Estados más pobres son los más dependientes y viceversa.

Para el periodo de estudio se atribuye la dependencia financiera de las haciendas públicas estatales a variables institucionales inherentes a la estructura y evolución del SNCF, tomando en cuenta que el gran incremento en la recaudación, tanto estatal como federal, tuvo un reducido impacto en

\section{CUADRO 5}

RESUMEN DE RESULTADOS, ENTIDADES FEDERATIVAS, 2004-2016

(miles de pesos constantes a precios de 2010 y porcentajes)

\begin{tabular}{|c|c|c|c|c|c|}
\hline Entidad & Pobreza (\%) & $\begin{array}{c}\text { Ingresos } \\
\text { propios } \\
(2010=100)\end{array}$ & $\begin{array}{l}\text { Ingresos } \\
\text { transferencias } \\
(2010=100)\end{array}$ & $\begin{array}{c}\text { IEDFe } \\
(\%)\end{array}$ & $\begin{array}{c}\text { IEDFa } \\
(\%)\end{array}$ \\
\hline Nuevo León & 21.02 & 9160728.13 & 34401036.14 & 79.67 & 30.93 \\
\hline Coahuila & 27.81 & 2671589.39 & 20618806.06 & 89.14 & 43.96 \\
\hline Ciudad de México & 28.54 & 51506131.69 & 62350710.43 & 54.99 & 7.72 \\
\hline Baja California Sur & 30.99 & 826896.30 & 6543562.41 & 88.95 & 47.38 \\
\hline Baja California & 31.52 & 3219280.48 & 23581361.11 & 87.85 & 41.12 \\
\hline Sonora & 33.15 & 3187670.97 & 22977305.64 & 88.10 & 37.74 \\
\hline Quintana Roo & 34.63 & 2914365.10 & 11197917.21 & 81.40 & 39.54 \\
\hline Colima & 34.69 & 697433.58 & 6630897.17 & 90.82 & 47.40 \\
\hline Sinaloa & 36.67 & 2599847.02 & 21485719.88 & 89.32 & 43.93 \\
\hline Jalisco & 37.05 & 5900126.35 & 49572699.87 & 89.64 & 39.35 \\
\hline Aguascalientes & 38.13 & 1026756.55 & 10081458.98 & 91.33 & 45.21 \\
\hline Chihuahua & 38.81 & 6382420.18 & 25054740.75 & 79.83 & 38.87 \\
\hline Tamaulipas & 38.95 & 3339201.60 & 25754977.31 & 88.60 & 45.05 \\
\hline Nayarit & 41.36 & 708935.70 & 10115746.24 & 93.54 & 52.29 \\
\hline Querétaro & 41.41 & 2439240.57 & 14170109.13 & 85.83 & 40.24 \\
\hline México & 42.89 & 17043784.99 & 97625777.22 & 85.72 & 37.97 \\
\hline Morelos & 43.24 & 867445.91 & 13377608.20 & 94.02 & 49.45 \\
\hline Media Nacional & 46.11 & 3115093.62 & 26658988.17 & 88.88 & 45.49 \\
\hline Yucatán & 48.32 & 1555293.76 & 15234605.35 & 91.07 & 47.75 \\
\hline Guanajuato & 48.51 & 4801983.75 & 34659777.06 & 88.61 & 44.35 \\
\hline Campeche & 50.50 & 1544968.64 & 10341433.22 & 87.40 & 41.97 \\
\hline
\end{tabular}


CUADRO 5 (continuación)

RESUMEN DE RESULTADOS, ENTIDADES FEDERATIVAS, 2004-2016

(miles de pesos constantes a precios de 2010 y porcentajes)

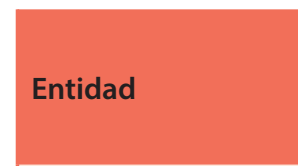

Durango

San Luis Potosí

Hidalgo

Michoacán

Tabasco

Veracruz

Zacatecas

Tlaxcala

Puebla

Oaxaca

Chiapas
Guerrero

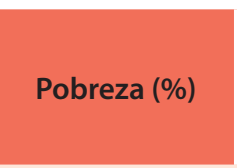

51.57

52.40

54.67

54.73

57.10

57.58

60.25

60.31

61.48

66.99

67.57

78.48

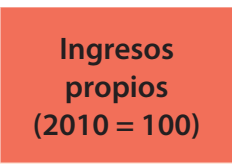

1290738.06

1717337.01

1782688.83

2273910.84

1804392.10

4759638.44

993702.08

510992.38

3701357.75

2007188.54

1399200.02

3438787.11

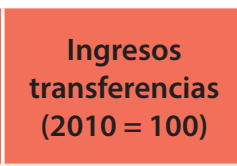

14104973.21

20118371.15

21074212.44

31652911.18

26531621.62

56383006.46

13592757.46

9759167.11

38926865.46

32982860.57

29840945.82

42343679.46

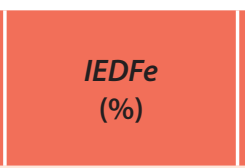

91.82

92.16

92.23

93.34

93.76

92.28

93.22

95.04

91.71

94.42

95.59

92.62

Fuente: elaboración propia con datos de las Estadísticas Oportunas de las Finanzas Públicas de la sHcP, de la Información de Federalismo Hacendario del INAFED y de las Finanzas Públicas Estatales de México (varios años), Cuentas Públicas y Leyes de Ingreso de las Entidades Federativas (varios años) del Instituto Nacional de Estadística y Geografía (INEGI).

la disminución de la dependencia financiera, en sus dos dimensiones $(-6.1 \%$ en sentido estricto y $-11.3 \%$ en sentido amplio), se precisa que si esta condición generalizada no depende en gran medida de la recaudación es probable que se deba a lo siguiente:

- Por la naturaleza del pacto fiscal, y como se sugiere en la literatura, este se realizó bajo un esquema de eficiencia económica y equidad distributiva, otorgando a la federación las potestades tributarias más importantes y haciendo participar a las entidades federativas a cambio de la cesión de esos impuestos (concurrencia impositiva), por lo cual siempre el grueso de los ingresos estatales recaerá en los impuestos que cedieron para consolidar el pacto fiscal (que son los de mayor recaudación).

- Pese a que no se realizó ningún análisis de correlación entre la actividad económica y los ingresos estatales, se plantea como una conjetura que el crecimiento económico es un determinante principal de las recaudaciones federal y estatal, por ser esta la variable que relaciona las finanzas públicas con el ciclo económico.

Si bien la recaudación estatal no ha sido precaria, aún existen áreas de oportunidad que las entidades podrían aprovechar para incrementar su recaudación (como el caso de la tenencia), que en primera instancia dependerán de la capacidad administrativa y la profesionalización de los servidores públicos de los niveles subnacionales. 
- Aún se soslaya el hecho de que los criterios por los que se distribuyen las transferencias federales son instrumentos de alto impacto e incidencia en el comportamiento de los gobiernos subnacionales; las fórmulas de distribución aún cuentan con criterios principalmente distributivos, que no promueven, a manera de incentivos, el crecimiento económico, la formalidad o la recaudación estatal.

Se recalca el uso de esta medición de manera propositiva, más no limitativa, para cuantificar la relación entre fuentes de ingreso de las entidades federativas, a fin de explicitar la implicación de que los ingresos provengan de transferencias o de la propia recaudación estatal.

\section{CONCLUSIONES Y RECOMENDACIONES}

El tema de la dependencia financiera aparece, dentro de la agenda federal, siempre presente pero largamente pospuesto. Si bien el desarrollo del federalismo fiscal, en el México del siglo xx, logró la eliminación de la múltiple tributación y la consolidación del SNCF (que nació con el espíritu de fomentar la coordinación fiscal y la unidad nacional), continuó de manera inercial y tradicionalista, con una paulatina adaptación a la evolución económica y política de la hacienda.

A saber, al gobierno federal se le han atribuido, a raíz del pacto fiscal, las potestades tributarias más importantes (según su nivel recaudatorio) por su eficiencia en la recaudación, sin embargo, las entidades cuentan con instrumentos fiscales importantes (como la tenencia y el Impuesto sobre Nóminas).

Del análisis de la situación financiera se obtiene que en promedio los ingresos propios estatales representaron el 11.2\%. Dentro de esta clasificación, los impuestos fueron el rubro más importante de la recaudación estatal, al tener en promedio un peso relativo del $42.9 \%$ en el total de ingresos estatales. Así, encontramos que el sistema tributario en México se basa fundamentalmente en impuestos sobre los ingresos y el patrimonio, asimismo que su desempeño ha sido favorable al tener una tasa de crecimiento promedio anual del $9.6 \%$ y una acumulada real de $191 \%$ durante el periodo de estudio.

Se observó que en periodos de recesión económica (2008-2009) y de afectaciones al mercado del petróleo, como ocurrió en 2012 (por su estrecha relación con los ingresos públicos), los ingresos totales tuvieron reducciones considerables debido a que la Recaudación Federal Participable funge como piedra angular del SNCF, siendo ésta la base sobre la que se distribuyen las participaciones y al mismo tiempo el instrumento mediante el cual se relacionan la economía real (actividad económica) y los ingresos públicos.

Sobre las transferencias, se reitera que el grueso de los ingresos de las entidades descansó en este rubro (65.5\% en promedio real), donde los fondos de participaciones y aportaciones federales más importantes basan su distribución principalmente en dos criterios: uno inercial, que asegura un monto no menor al de los ejercicios 2007 y 2013 (según sea el caso), y un componente mixto resarcitorio/distributivo, que determina el incremento de los recursos destinados por estos fondos, lo cual da una estrecha actuación a los componentes resarcitorios y compensatorios, en los cuales se debería basar fundamentalmente la distribución de estos recursos. Esta distribución, que en un inicio sirvió como un incentivo para fomentar la coordinación fiscal y lograr la unidad nacional en un verdadero federalismo fiscal, continuó de manera inercial y tradiciona- 
lista ("así se han venido haciendo las cosas, así se han hecho siempre"). Soslayando, en cierta medida, la capacidad de las haciendas públicas de utilizar sus instrumentos fiscales para fomentar mejores prácticas de gestión hacendaria.

Con base en el análisis financiero que se realizó, y la determinación de los niveles del IEDF, se concluye que, en México, ha prevalecido esta condición para todas las entidades federativas, en sentido amplio y estricto (en un menor grado para la Ciudad de México, como caso atípico); la media nacional del índice se sitúa en 45.5 puntos en sentido amplio y 88.8 en sentido estricto. Se identificó que las entidades federativas que tienen altos niveles de recaudación muestran niveles de dependencia similares a los de las entidades con menores ingresos propios. A partir de lo anterior, se tienen indicios de atribuir la dependencia financiera a factores institucionales y no a la propia gestión de las haciendas públicas estatales (esfuerzo fiscal).

Se identifica al IEDF amplio, al medir la dependencia de las haciendas estatales respecto de los recursos etiquetados, como una medida más adecuada a la realidad fiscal y apegada a la teoría de la descentralización fiscal bajo los principios de subsidiaridad y correspondencia fiscal, por su relación intrínseca con el gasto público en áreas prioritarias del desarrollo subnacional y con el margen de acción limitado que tienen estos recursos al no ser de libre disposición.

La evolución de la dependencia financiera estatal se considera favorable, al identificarse una disminución acumulada real del $6.1 \%$ en sentido estricto y de $11.3 \%$ en sentido amplio. Se atribuye esta condición a la naturaleza del pacto fiscal, a la actividad económica de las entidades federativas, a los sistemas de distribución de transferencias federales (que se realizan bajo criterios inerciales y distribu- tivos) y, en menor medida, a la gestión de las haciendas públicas estatales determinada por la capacidad administrativa y la profesionalización de los funcionarios públicos.

Se aborda el estudio de la dependencia financiera de manera propositiva, más no limitativa, como preludio a una mayor profundización en el desarrollo e implementación de una política pública transversal de la hacienda multijurisdiccional que incorpore una visión integral del federalismo fiscal. Se habla de una transición hacia un federalismo hacendario o, como es llamado en la literatura económica, la segunda generación del federalismo fiscal, donde se profundicen e incorporen a la política hacendaria, en conjunto, los siguientes temas:

- la dependencia financiera;

- la responsabilidad hacendaria en materia de deuda pública;

- la contracción de pasivos contingentes, y el comprometer los ingresos futuros de las haciendas estatales que estos instrumentos implican;

- la ampliación del alcance de la coordinación hacendaria hasta el nivel local, y

- la promoción de una cultura de verdadera transparencia y rendición de cuentas, así como una mayor inclusión del sector social en la fiscalidad.

No escapan al autor otras variables que comprometen recursos públicos descentralizados. Aunado al problema de dependencia financiera, asociado con la indisposición de recursos financieros de las haciendas estatales, se advierte que la deuda pública subnacional también compromete ingresos de libre disposición de las entidades federativas (ingresos propios, participaciones y FAFEF por su carácter resarcitorio); por su parte, los pasivos contingentes, como el caso específico 
del programa "Escuelas al Cien" y el uso de Bonos Cupón Cero para infraestructura educativa estatal, tienen comprometidos ingresos del FAM, en su componente de Infraestructura Educativa, y del FGP para el pago de intereses que generan los créditos otorgados a las entidades por parte del Banco Nacional de Obras y Servicios Público (BANOBRas; en su carácter de fideicomitente).

Ante este panorama, que se antoja adverso, se realizan las siguientes recomendaciones:

- Incorporar tecnologías de la información para consolidar un Sistema Nacional de Información Hacendaria a cargo del INDETEC. Se trata de generar información de inteligencia que fomente sinergias positivas en la evolución del actual SNCF y se utilice como referencia para la toma de decisiones de los funcionarios fiscales de los tres niveles de gobierno.

- Se exhorta a convocar a la Segunda Convención Nacional Hacendaria con el objetivo general de transitar hacia una segunda generación de federalismo fiscal (federalismo hacendario), la cual no sólo incluya a la SHCP, a los órganos técnicos del SNCF y a las secretarías de finanzas (y homólogos) de las entidades, sino que incorpore con derecho de voz y votoa los representantes del Sistema Nacional Anticorrupción (SNA), en particular a los funcionarios públicos del Comité Coordinador del sNA. En otras palabras, se propone la coordinación entre SNCF y SNA como un avance en la cooperación institucional en la consecución de los objetivos de nuestro sistema fiscal federal.

- Fomentar, a manera de incentivos, la modernización institucional de las haciendas públicas subnacionales, como una decisión bilateral entre federación y entidades federativas.

- Desde el seno del nuevo Sistema Nacional Anticorrupción y del Sistema Nacional de Fiscalización, promover mecanismos de fiscalización que aseguren que la distribución de los ingresos en los niveles subnacionales de gobierno y el ejercicio de los recursos descentralizados se realice conforme a la normativa. $\mathbf{e}$

\section{REFERENCIAS}

Auditoría Superior de la Federación (2017). Infraestructura Financiada con Ingresos Futuros. Informe Especial. México: Auditoría Superior de la Federación.

Ayala, J. (1996). Mercado, elección pública e instituciones. Una revisión de las teorías modernas del Estado. México: Porrúa.

Centro de Estudios de las Finanzas Públicas (2006). Ramo 33. Aportaciones Federales para Entidades Federativas y Municipios [CEFP/036/2006]. Serie de Coloquios de Finanzas Públicas 2006. México: Cámara de Diputados.

Chiapa, C. y Velázquez, C. (2011). Estudios del Ramo 33. México: El Colegio de México y Consejo Nacional de Evaluación de la Política de Desarrollo Social.

Colmenares Páramo, D. (1999). Retos del federalismo fiscal mexicano. Comercio Exterior, 49(5), pp. 415-431.

Convención Nacional Hacendaria (2004). Declaratoria a la Nación. México: Secretaría de Hacienda y Crédito Público. 
Courchene, T. y Díaz-Cayeros, A. (2000). Transfers and the nature of the Mexican federation. En: M.M. Guigale y S.B. Webb (eds.), Achievements and Challenges of Fiscal Decentralization: Lessons from Mexico (pp. 200-236). Washington, DC: World Bank.

Lewis, W.A. y Martin, A. (1956). Patterns of public revenue and expenditure. The Manchester School, 24(3), pp. 203-244.

Mendoze, E. y Martínez-Vázquez, J. (2000). Assignment of Spending Responsibilities and Service Delivery. En: M.M. Guigale y S.B. Webbs (eds.), Achievements and Challenges of Fiscal Decentralization: Lessons from Mexico (pp. 139-173). Washington, DC: World Bank.

Moreno, M. (1997). De la crisis del modelo borbónico al establecimiento de la República Federal. En: G. Villegas y M. Porrúa (coords.), Enciclopedia Parlamentaria de México. Serie III: Documentos, Volumen I: Leyes y documentos constitutivos de la nación mexicana. Tomo I. México: Instituto de Investigaciones Legislativas de la Cámara de Diputados, LVI Legislatura.

Oates, W. (1972). Federalismo fiscal. España: Instituto de Estudios de Administración Local.

Oates, W. (1999). An essay on fiscal federalism. Journal of Economic Literature, 37(3), pp. 1120-1149.

Peña, J.A. y Bojórquez, A.L. (2012). Autonomía Financiera Municipal. México: Instituto Nacional para el Federalismo y el Desarrollo Municipal, Secretaría de Gobernación (SEGOB).

Peña, J.A. y Wence, L. (2011). La distribución de transferencias federales para municipios, ¿Qué incentivos se desprenden para el fortalecimiento de sus haciendas públicas? Hacienda Municipal, 115, octubre-diciembre, pp. 79-96.

Quintana, R. (2008). Derecho municipal. México: Porrúa.

Sobarzo, H. (2006). Esfuerzo y potencialidad fiscal de los gobiernos estatales en México. Un sistema fiscal representativo. El Trimestre Económico, LXXIII(4)(292), octubre-diciembre, pp. 809-861.

Sour, L. (2004). El sistema de transferencias federales en México. ¿Premio o castigo para el esfuerzo fiscal de los gobiernos locales urbanos? Gestión y Política Pública, XIII(número especial), pp. 733-751.

Sour, L. (2008). Un repaso de los conceptos sobre capacidad y esfuerzo fiscal, y su aplicación en los gobiernos locales mexicanos. Estudios Demográficos y Urbanos, 23(2), pp. 271-297. http://dx.doi.org/10.24201/edu.v23i2.1312

Weingast, B. (1995). The Economic Role of Political Institutions: Market-Preserving Federalism and Economic Development. Inglaterra: Oxford University Press. 